\title{
Funções e conceito do direito civil comparado
}

\author{
Lino de Moraes Leme. \\ Catedrático de Direito Civil.
}

\section{RECONHECIMENTO DA NECESSIDADE DO ESTUDO DO DI- REITO COMPARADO.}

Antes de apontar as orientações no estudo do Direito Civil Comparado, e dar-lhe o conceito, notemos que o espirito humano, desde os primórdios da ciência do direito, compreendera as vantagens da comparação. Basta citar dois nomes: Aristóteles (1) (384-322 a. C.), que afirmou o princípio de que não ha ciência do particular e confrontou Constituições e Montesquieu (2) que se referiu expressamente aos processos e funções do método comparativo.

Montesquieu escreveu: "La loi en général est la rašsou humaine, en tant qu'elle gouverne tous les peuples de la terre, et les lois politiques et civiles de chaque nation ne doivent être que les cas particuliers où s'applique cette raison humaine. Elles doiventêtre tellement propres au peuple pour lequel elles sont faites, que c'est un très grand hasard si celles d'une nation peuvent convenir à une autre" (L. I. cap. 3).

Essa tese foi o ponto de partida da escola histórica (3), dominada por duas ideias fundamentais; uma a de que o

(1) Politica e Retorica.

(2) L'Esprit des lois.

(3) Lerminier, Introduction générale à l'Histoire du Droit, refere que a Machiavel e a Vico, na Italia, a Bordin e Montesquieu, na França, tem sido filiada a escóla histórica, cujas idéias capitais 
direito o produto da consciência nacional, do espírito com um cada povo; outra, a de que o Direito evolve, como as línguas.

$O$ reconhecimento da necessidade do estudo do direito comparado levou à criação, em França, em 1830, da Cadeira de História geral e filosófica da legislaçấo com parada, no Collège de França, regida por Lerminier, a quem sucederam primeiro Laboulaye e, depois, Jacques Flach, e, em 1837, na Faculdade de Direito de Paris, outra cadeira, regida por Ortolan.

No Brasil foi criada, em 1891, a Cadeira de Legislação Comparada, regida em S. Paulo por João Monteiro; em Recife, por Clovis Bevilaqua, e, no Rio de Janeiro, por Cândido de Oliveira (4).

2. ORIENTAÇôES PARA O ESTUDO DO DIREITO COMPARADO.

Numerosos trabalhos foram publicados sobre a matéria, expondo-se idéias dísprares sobre a orientação do estudo do Direito Comparado, de tal sorte que o Congrès International de Droit Comparé, reunido em Paris, em 1900, colocou, entre os temas a elucidar, o relativo ao conceito, definição e método da matéria.

Para facilidade de conhecimento, entendemos de classificar essas orientações, em quatro grupos:

I - a ciêntifica,

II - a legislativa,

foram desenvolvidas por Savigny, em sua polêmica com Thibaut. Este escreveu sobre "A necessidade dum código civil comum a tôda a Alemanha (1814); respondeu-lhe Savigny com Da vocoção do nosso século para a legislação e a jurisprudência, em cujo trabalho desenvolve idéias que depois imodificou e que sofreram veira, o Curso de legislaçấo comparada.

(4) Como reflexo de seu magistèrio, deixaram: João Monteiro, a lição inaugural ( $D a$ futura universalização do direito); Clovis, as Lições de legislação comparada e, Cândido de Oliveira, o Curso de legislação comparada. 
III - a subsidiária do direito nacional e do direito internacional privado,

IV - a teórica e prática.

Vamos expôr sucintamente a orientação dessas correntes, antes de abordarmos o conceito do Direito comparado.

3. A CORRENTE CILNTIFICA

A' corrente cientifica se filiam Kohler (5), Post (6), Del Vecchio (7), Carusi (8), Rotondi (9), Sauser-Hall (10), Andrès Weyss (11), além de outros.

Segundos eles ha uma ciência do "direito comparado", isto é, tem o direito comparado a finalidade de investigar o direito de todos os povos, para mostrar-nos o seu desenvolvimento e fazer-nos conhecer como se orientam as suas transformações.

Kohler, como os neo-hegelianos, substituindo a idéia, como essência das cousas, pela cultura, define esta como a evolução das forças para uma fórma pre-definida de humanidade, ou como uma corrente contínua da magnificência divina, com o fim de realizar as aspirações de Deus. A evolução do direito, diz ele, está submetida às leis do progresso, com base em uma única direção e subordinada

(5) Filosofia del derecho e Moderni problemi del dirito.

(6) Einleintung in Das Studium der ethnologishen Jurisprudenz.

(7) Filosofia de direito, trad. port., 1948.

(8) II problema del diritto comparato, in Atti della Soc. Jtal. per il progresso della Scienza, 1914

(9) Per lo studio delle riforme legislative e del diritto comparato, in Riv. di dir. civ, 1926; Il dïritto comme oggetto di conoscenza, 1924.

(10) Fonction et méthode du droit comparé, in Congrès du Droit comparé, 'v. I.

(11) Rôle, fonction et méthode du droit comporé. 
à obediência a certos fins e à liberdades de meios, que, reunidos, produzem a legalidade. A história universal do direito (denominação que ele prefere à de ciência do direito comparado) tem por objeto a investigação do direito dos povos existentes e dos desaparecidos, que permita reconstituir o progresso fatal da cultura da humanidade, de fórma a continuá-la dentro do plano divino. Cada direits nacional não é senão um membro da cultura humana e seus carateres servem para esclarecer a imagem total da humanidade.

Em sentido semelhante se manifesta Del Vecchio que, sem se referir a plano divino, recorda a afirmação de Vico, segundo a qual se encontram as mesmas instituições em povos diferentes, sem haver contactos ou conhecimento mútuo, isto é, sem que um "tivesse tomado de outro o exemplo." Ao lado dessas uniformidades, que diz "naturais", salienta ele o fenómeno histórico da influência dos povos uns sobre os outros, e dos respectivos direitos, e isso porque o Direito não é apenas um fenomeno nacional, mos sobretudo humano. Assim, com o método genetico e comparativo pode-se tentar a narrativa de uma história universal do direito.

Adolf Bastian (12) (1826-1905), partindo da natureza psíquica uniforme de todos os homens, sustentava a poligênese da civilização humana, que, em virtude dessa na tureza uniforme, evolve em todos os logares na mesma direção, um pouco desviada pelas particularidades das condições geográficas, climáticas e econômicas.

Essas idéias são aplicadas por Alberto Ermanno Post principalmente ao direito, de onde a teoria da etnologia juridica, que, partindo da raça, como centro, sustenta que ha tantas evoluções quantas são as raças. Estas constituem um fenômino natural e espontâneo, filho do solo e do clima, e cuja transformações se operam lentamente, esca-

(12) Elementar, und Volkergedanke. 
pando absolutamente à nossa observação. Assim ele se aparta dos que consideram uma história universal do direito, para sustentar que essa história apenas pode ser geral, ou uma para cada raça.

Dessas concepções se apartam Carusi e Rotondi.

Para Kohler, o direito comparado fornece os fatos, com base nos quais se recompõe o processo de desenvolvimento do direito e se funda uma história universal do Direito, que, ligada à sua concepção do mundo, se converte em uma verdadeira filosofia do direito. Segundo Post, o direito comparado observa os fatois, estabelece-lhes a correlação e o desenvolvimento, e descobre na raça a causa de seu encadeamento. Outra é a atitude de Carusi, que dá à ciência do Direito comparado, animada de espírito filosófico, com base em estatisticas materiais, a finalidade de investigar as relações substanciais e constantes, em meio à flutuação de elementos variaveis, observando o seguinte processo: a) exame análítico das instituições e dos sistemas de Direito, aplicando o método histórico-analítico de Bonfante; b) investigar as instituições; e c) investigar as constantes psicológicas no desenvolvimento delas. Na mesma ordem de idéias, Rotondi dá, ao direito comparado, a função de pesquizar as leis naturais que ligam um direito a outro, ou uma a outra familia, ou categoria, nas quais possamos classificar todos os direitos históricos e vigentes, dando-nos a possibilidade de prever, com suficiente precisão, os efeitos e as metas da evolução jurídica.

\section{A CORRENTE LEGISLATIVA}

À corrente legislativa (13) pertencem aqueles que procuram, através do direito comparado, fundar um sis-

(13) Político-legislativo é a denominação preferida por Binder, Radbruch, Rabel, Nartinez Paz. 
tema legislativo universal (Saleilles) (14), ou comum (Lambert (15). Não partem eles de princípios imanentes, e sim procuram construir um sistema jurídico com base em princípios fundamentais, para um, e finais, para o outro.

Saleilles, como Stammler, parte de um direito natural variavel no tempo, a que se chega não partindo da razão, mas da realidade representada pelas legislações vigentes, e que leva a um direito comum, superior às diversidades legislativas, e destinado a suprir as lacunas do direito interno.

Para Lambert, o direito comparado compreende a história comparada do direito, que, investigando as causas das relações de sucessão entre os fenômenos juridicos, descobre as leis naturais que regem as manifestações da vida social, cujo conjunto constitue o direito; e legislação comparada, que é um dos órgãos de revelação, criação e aplicação do direito, por meio do qual se desprende, da confrontação dos sistemas juridicos, o fundo comum das concepções e das instituições. A legislação comparada conduz ao direito comum legislativo.

As diferenças entre os sistemas de Soleilles e de Lambert podem ser assim resumidas; a) o primeiro compara os direitos, o segundo sómente se atěm às legislações; b) o primeiro objetiva a criação de um direito universal, destinado a preencher as lacunas dos direitos nacionais; o segundo pretende criar um direito conum legislativo; c) Lambert nega a existencia de idéias verdadeiramente comuns à humanidade civilizada, exceto se se erigirem em máximas do direito comum à humanidade as produções do pensamento romano, o que significa que a sua idéia não é a de um direito universal.

(14) Conception et objet de la science du droit comparé, in Bulletin de la Sociéte de Législation Comp. XXIX, 393.

(15) La foncion du droit civil comparé, 1903. 
As idéias de Consentino (16) não discrepam das de Lambert. Tambem eles reconhecem uma função científica no direito comparado, e, entusiasmado com o seu codigo civil pan-americano, considera um grave erro de Montesquieu o sustentar que as leis devem ser o reflexo do meio social, pelo que devem diferir de um pais para outro, como duas folhas que jamais aparecerão como idênticas; para ele a unificação se realiza por tres processos; a) imitação; b) a adoção pura e simples, num Estado, da legislação de outro; c) por concessões reciprocas dos diversos Estados (17).

As idéias de Lambert dominaram no Congresso de Direito comparado, reunido em Paris, em 1900.

\section{O DIREITO COMPARADIO SUBSIDIÁRIO DO DIREITO NA- CIONAL.}

A orientação que considera o direito comparado como subsidiário do direito nacional se desdobra em várias correntes; a) a primeira, a de aperfeiçôar o direito nacional; b) para outra, a de interpretar esse direito; c) e ainda a de preencher as lacunas do direito.

A primeira corrente é representada por Josserand, Cruet e outros. A leis, dizem, precisam ser constantemente renovadar, para aperfeiçôa-las ou para melhor adaptá-las às necessidades sociais. A inspiração para essas reformas provém não sómente da doutrina nacional, como tambem da doutrina e da legislação estrangeiras. A política legislativa se converte, dest'arte, em uma ciência legislativa. O direito comparado, diz Josserand, é o direito em marcha, considerado em seu aspeto mais vivo, mais verdadeiro; é a

\footnotetext{
(17) L'unification internationale du droit privé, 1924.

(18) Josserand,Conception générale du droit comparé, Congrès v. I. Cruet, La vie du droit, 1908.
} Law.

(16) La science du droit comparé et l'American Common 
ciência do direito que nos descobre o porvir das legislações. "Le vrai titre du droit comparé, diz Cruet, n'est pas de donner aux diversas législations une orientation uniforme, il est de suggérer, par l'étude des législations étrangères, des solutions vraiment nationales".

Quando se examinam os julgados dos tribunais de um país, vê-se a influência que a jurisprtidência de um exerce sobre outro. O mesmo fato não se observará quanto á jurisprudência estrangeira, em confronto com a nacional? O magistrado, que deve adaptar a lei às necessidades sociais, tem de forçosamente, acolher as soluções oferecidas pelo direito comparado, venham elas através da doutrina, como sustenta Josserand, ou diretamente, como pretende Weiss (19).

\section{O DIRITO COMPARADO COMO SIMPLES METODO}

E outra concepção é a do direito comparado como um simples método para o conhecimento do direito, estudando-se ele não apenas em relação ao direito nacional, mas igualmente através de manifestações jurídicas paralelas. A principio, por influência da filosofia do direito, ou de juristas filósofos, a comparação se limitará ao campo histórico do direito (20); depois, no entanto, sob a influência dos puros juristas, sem nenhum limite doutrinário (21). O direito comparado, em tal sentido, pode auxiliar a completar as lacunas do direito (22). A idéia fundamental,

(19) Rôle, fonction et méthode du droit comparé, dons le domaine du droit civil - Congrès, I

(20) Leopoldo Wenger, Romische Recht - No mesmo sentido Jhering, Espirito do direito romano; Stanilas Pinelás, Quesaions du droit romain.

(21) Messineo, L'Indagine comparative negli studil giuridici, in Archivio Giuridico "Serafini", 1931 IX, 18.

(22) Paul Koshaker, L'histoire du droit et le droit comparé surtout en Allemagne. 
porém, dessa orientação, que predominou nos Congressos reunidos em Haia, em 1932 e 1937, graças aos esforços da Academia Internacional de Direito Comparado, fundada na Itália, em 1924, foi a de que o direito comparado é um método pelo qual a ciência do direito se adapta às necessidades da comunidade internacional, o que não passa de uma formula de Lambert que, na sessão de encerramento do Congresso de 1937, desta fórma resumia as finalidades do direito comparado: Assim como, acima da diversidade de costumes medievais, emergiu um fundo de direito comum à cristandade do Ocidente, tambem será possivel a adaptação das instituições juridicas à estrutura econômica dos povos e à internacionalização das partes comerciais do seu direito.

\section{O DIREITO COMPARADO SOB O ASPECTO TEORICO E PRÁTICOO.}

Ao lado dessas orientações, ha a que considera o direito comparado sob o aspecto teórico e prático. Assim Mario Sarfatti (23) distingue o estudo científico do direito comparado do estudo do direito interno pelo método com. parativo. O primeiro, doutrinárioo e de feição históricoetnológica, se propõe a tirar, do conjunto dos sistemas jurídicos fundamentais, um vêio de ideias comuns que sejam eventualmente aproveitaveis para a futura formação de critérios juridicos universais. $O$ segundo, juridico, se propõe fornecer subsidios ao legislador e método para interpretar as leis. Tambem Martinez Paz dá ao direito comparado, uma função teorética - ade apontar a idéia essencial em que assenta cada instituição jurídica, nas legislacões de umgrupo de povos de cultura juridica semelhante, e coordenar essas noções em um sistema jurídico que, embora oriundo da realidade, represente uma generalização

(23) Le droit compare dans son essence et son application $e$ Introduzione allo studio del diritto comparato, 1933. 
mais ampla do que as contidas nos direitos nacionais; - e uma função prática, na política legislativa, na realização, conhecimento e apreciação do direito positivo (24).

\section{OS CIRCULOS CULTURAIS.}

E uma referencia deve ser feita a uma teoria formada na Alemanha, denominada círculos culturais, governando a evolução jurídica, pela de centros de irradiação, determinadas por utensílios, armas, fórmas de construção de casas, ligadas a outros elementos culturais e a certas instituições sociais (25).

\section{OS ESCRITORES BRASILEIROS.}

No Brasil vemos João Monteiro sustentar a tese "Da futura universalização do direito", na aula inaugural, em 30 de Maio de 1895 (26), e, no trabalho sob o titulo "Cosmópolis do direito", reforçar os argumentos apresentados nessa aula.

Clovis Bevilaqua vê, no direito comparado, tres ordens de vantagens: para a ciência, para o legislador e para o juiz. Sob o primeiro aspeto, observa que a generalização de certos institutos jurídicos é uma consequência forçosa de identidade fundamental da natureza humana, e, mais ainda, da estrutura social, em seus traços mais gerais, ao menos onde ela se tem revelado capaz de substituir e desenvolver-se. Ao lado dessas analogias, observam-se divirgências resultantes do que à cultura devem as grandes raças que a argamassaram (27).

Cândido de Oliveira contesta seja possivel a universalização do direito, embora reconheça a existência de certos

(24) Introdución al estudio del derecho comparado, 1934

(25) W. Schmidt, en Eyre, European civilization.

(26) Revista da Faculdade de Direito de S. Paulo, v. 3.

(27) Lições de legislação comparada, 1893. 
princípios, geralmente aceitos, e que constituem o fundo comum das sociedades humanas. Mas, se o princípio domina, a aplicação reveste fórmas práticas as mais variegadas; e, sob esse aspeto, aponta a comparação como o farol que ilumina o jurisconsulto, no trabalho incessante da adaptação da lei ao momento histórico da sociedade que ela vai reger. A utilidade da disciplina se manifesta em uma tríplice esfera - para o legislador, para o magistrado e para o jurisconsulto. Principalmente para este, pois a ele está confiado o desenvolvimento científico do direito.

\section{CRítica á ORIEnTAÇÃo Cientifica.}

Em escritores que não reconhecem função científica ao direito comparado, nota-se a preocupação de criticar essa orientação e de relegá-la para o passado. E assim que Messineco diz: Alle istanze di sapore scientifico si accenna ormai in sordina quasi como a pezzo d'obbligo, allo scopo di corroborare com ragioni accessorie il valore di questi studi, che, per sè, è riposto in finalitá di altro ordine (28); e Martinez Paz escreve: "La ciencia del derecho no puede hacerse sobre la base do los elementos empiricos que proporciona la comparación de las legislaciones". E Koshaker: (29) " Tout cela est aujourd'hui suranné.

\section{DIREITO COMPARADO E CIENCIA DO DIREITO.}

Sem duvida têm razão aqueles que negam a existência de uma ciência do direito comparado. A comparação é um dos processos de método indutivo. Assim, da aplicação desse processo ao direito pode resultar uma ciência do direito, uma vez que se descubram princípios a que obedeçam as transformações do direito. A comparação é um

(28) O. c. p. 16 .

(29) O. c. 
processo, e, quando ela obedeça a criterios certos,será lícito falar-se em método comparativo (30).

Uma cousa é o direito comparado e outra a ciência do direito. Em tal sentido, o direito comparado, em vez de disciplina científica, é um método.

Para aplicação do direito comparado, com essa função, é mister partir do princípio de que as concordâncias e as diferenças observadas atestam haver uma evolução no direito, ou seja - que as suas transformações obedecem a principios semelhantes aos das leis naturais, isto é, que o direito é uma ciência, contra as opiniões de Spengler, Stammler, Kirchmann.

12. SERA ANTIQUADA ESSA CONCEPÇÃO DO DIREITO COMPARADO?

A resposta pode ser dada examinando-se trabalhos sobre o assunto, bem assim os referentes à filosofia do direito, e observando-se como se constituiram as ciências afins.

Em trabalhos de 1936, Alexandre Otetetisandi (31) mostra que o notavel professor Lambert, a quem tanto deve o direito comparado, em prol do qual desenvolveu atividade durante quarenta anos, na Faculdade de Direito de Lyon, considerava o direito comparado como ciência e como arte. Tambem como ciência o considera Albert Kocourek (32), embora divirja do critério por ele adotado. No mesmo sentido se manifestam Mario Sarfatti (33) e outros.

Se passarmos aos filósofos do direito, encontramos manifestações no mesmo sentido. Vimos que nessa corrente

(30) Método é um conjunto de processos para descobrir a verdade.

(31) Les concptions de M. Lambert sur le droit comparé.

(32) Le développement du droit est-il gouverné par des lois?

(33) Le droit comparé dans son essence et son application. 
se encontram Josef Kohler (1849-1919), a respeito de quem diz Wilhelm Sauer (34): “Professa rigorosamente los principios del Derecho comparado, al mismo tiempo que, con genial intuición, ve en el Derecho um fenómeno de cultura, en libre conexión com la idea de la evolución de Hegel".

A. Groppali (35) examina o problema do progresso do direito e, depois de apontar fatores da evolução jurídica e de criticar as teorias evolucionistas - por seu determinismo mecânico, refere a teoria de Wundt e de Paulsen, que procuraram estabelecer a teoria das causas finais, pela concepção da vida universal como animada por um impulso teleológico, que emerge em graus paulatinamente mais elevados - e adere ìs ideias de Lewis e Ardigò. Estes afirmaram o princípio da complicação crescente e da autonomia dos fenômenos, nos quais não ha continuidade e equivalência mecânica, nem descontinuidade arbitrária de fórmas, nem suspensão des leis naturais. Para Lewis, as formações se encadeiam progressivamente umas às outras, sendo as mais complexas qualitativamente diferençadas das menos complexas, porque, em vez de resultarem da soma, emergem da combinação e da síntese dos elementos dela. Ardigò concebe o processo cósmico como uma ordem gradualmente progressiva de formações sempre mais elevadas e autônomas, pelas quais se passa da matéria à vida, ao espirito, à sociedade, ao pensamento, não se destacando as formações superiores das inferiores, mas delas constituindo a integração, conservando, no complexo de energias e de caratéres próprios, o conjunto das propriedades e das forças que animaram as formações anteriores. Portanto, o fenómeno jurídico é uma super-ordenação cada vez mais complicada e ascendente, de formações naturais.

(34) Filosofia juridica e social.

(35) Filosofia del diritto. 
Tambem fizemos referência a Giorgio Del Vecchio. Baste-nos acrescentar o trabalho de Edgar Bodenheimer (36), elaborado após a ditadura de Hitler, e no qual, referindo-se à Sociologia do Direito, diz que ela "tiene que mostrar las causas sociales y economicas que determinan la evolución de las normás y instituciones juridicas y que analizar las tendencias sociales existentes tras la legisla.ción".

o SÍMILE DA GLOTOLOGIA.

Consideremos uma ciência afim do direito, a glotologia. A linguagem é um fato social. Ela varia em virtude de condições fisico-geográficas climatéricas, políticas' e culturais. As linguas se influem reciprocamente. Pois bem: os glotólogos verificaram que as transformações das línguas obedecem a leis. Não se preocuparam eles com o problema da origem da linguagem, da mesma fórma que os biologistas não cogitaram do da origem da vida. Não cuidaram eles a não ser um ou outro espirito imaginário — em formar uma língua universal, porque esse não é o escopo da ciência. Tambem o direito sofre as influências de meio físico (geográficas, climáticas, geológicas), do meio social (politicas, morais, econômicas). Não interessa para a ciência, o problema da origem do direito. Não cuida ela de estabelecer um direito universal; o estabelecimento de princípios gerais não tem esse significado: a fórma pode, até certo limite, ser aproximada, mas o conteúdo tem as suas caraterísticas próprias.

F. Kern (37), Flor (38) e Koshaler (39) demonstraram ser insustentável a teoria dos círculos culturais, que é baseada em hipóteses não demonstradas, salientando o úl-

(36) Teoria del derecho, trad. esp. $1942-351$.

(37) Die Anfange der Weltgeschichte, 1935.

(38) Festschitl fur Hirt.

(39) O. c. 
timo que as influências e empréstimos em que se baseia essa teoria são insuficientes no domínio de outra organização social, econômica e jurídica; e lembra que os japoneses, por ex., não abandonaram sua organização da família e sua mentalidade, pelo fato de haverem sofrido grande influênca em seus contatos com os europeus, Para Kosha. ker, o direito não é uma ciência, embora reconheça a existência de concordàncias; e entende que não é, porque os fatores tipicos (o meio geográfico, social e econômico) são desviados sempre por fatores atípicos (por ex. a raça, as aptidões particulares, e sobretudo a história, que consiste em migrações e receções e fórma o carater de um povo, de maneira decisiva). Ora, se existem concordâncias, pouco importa que, entre as forças componentes, se incluam elementos diversos, da mesma fórma que, para o descobrimento das leis da evolução linguística, não importa exista melementos pertencentes a línguas estrangeiras, e para a formação da variedades e tipos nos domínios da biologia, eoncorram igualmente muitos fatores.

14. O DIREITO COMPARIADO É UM METODO E NÃO UMA CIENCIA.

O direito comparado é, dissemos, um método e não uma ciência, como pretenderam ainda recentemente Arminjon, Norde e Wolff (40), dizendo que ele não é um meio ou um método, mas uma ciência, seguindo a Kaden, (41) por isso que capaz de edificar um sistema de concepções de valor objetivo; e rejeitando, com razão, a identificação do mesmo com a história universal do direito, dizem que ele é um ramo da ciência do direito vivo, estudado, afim de fornecer regras de conduta, de servir para a ação. Quais sejam essas regras de conduta, esclarecem

(40) Traité de droit comparé, 1950.

(41) Rechtsversleichung, em Rvgh H. W. VI, v. 10. 
eles - são as regras da justiça, que regem normativamente as sociedades modernas. $E$ o fim do direito comparado é regular e melhorar a conduta dos homens.

Como um método considera-o René David, em obra recente (42).

\section{5 - CIENCIA E ARTE.}

Não se deve confundir a ciência com a arte. Aquela procura estabelecer as regras da evolução jurídica. A arte são aplicações da ciência. O interesse daquela é a teoria; o desta, a prática. A cada ciência corresponde uma arte: à mecanica pura, a aplicada; à geologia, a metalurgia; à fisica - a ótica, a acústica, a eletricidade; à química - a niquelação, a douração, a distilação; à medicina - a arte médica; ao direito - a advocacia.

o direito comparado tem tambem as suas aplicações ou funções práticas, dizem; mas são outras tantas artes da ciência do direito.

\section{6 - FUNÇÃO TEGNICA DO DIREITO COMPARADO.}

A função técnica do direito comparado é, pois, a de procurar a constância e a variedade nas regras de direito e nos institutos jurídicos.

Com esse escopo o direito comparado constitui o processo fundamental da ciência do direito, que é a de procurar a constância e a variedade nas regras do direito e nos institutos jurídicos, concorrendo para a descoberta dos princípios reguladores da evolução jurídica. Das suas aplicações, uma é a de constituir elemento subsidiário do direito nacional, por isso que os princípios gerais do direito são um dos meios para preencher as lacunas desse direito (art. $4 \mathrm{da}$ lei de introdução ao Codigo Civil) e do direito internacional (o art. 38 do Estatuto da Côrte Internacional de Háia manda consultar os princípios das leis nacionais).

(42) o. c. 
Além dessa função prática, o direito comparado presta um auxílio inestimável na politica legislativa e no conhecimento do direito positivo.

O direito está em constante evolução para se adaptar às novas neciessidades sociais. Reconhecidas elas, é natural que se aproveite a experiência de outros povos que já editaram normas para satisfazê-las, e que viram colimada essa finalidade. Adotadas, ver-se-á se produzem os mesmos resultados já verificados noutra partes, ou se $\dot{e}$ mister modificá-las. Reconhecido, por exemplo, que ha direitos certos e incontestaveis exigindo proteção, qual o caminho a seguir? Ampliar o instituto de habeas corpus, sob o fundamento de que em regra, nesses casos a lesão do direito se apresenta com o mesmo carater desse instituto, isto é, ligada ao direito de ir e vir, ou extender-se a proteção possessória aos direitos em geral, ou adotar-se um remédio. especial? Entre nós, em virtude do predomínio das idéias de Savigny - contra a orientação do direito comparado, do canônico e do feudal - , foi seguida a primeira orientação, depois substituida pela terceira, por influência do direitocomparado.

\section{8 - TRANSFORMAÇõES DO DIREITO.}

Outra finalidade prática é a de propiciar elementos. para o conhecimento do direito nacional. Surge dúvida, por ex. a respeito da servidão por destinação do proprietário: é possivel, ou não, em face da lei? Divergem a respeito autores e julgados. Pois bem: recorre-se ao direito comparado, que fornece os subsídios para a elucidação da controvérsia. Permite o Codigo a cláusula de retrovenda nos contratos referentes a imoveis. Deve essa cláusula ser proibida como no codigo português e no mexicano, ou deve ser mantida e até extendida aos contratos referentes a moveis". Como essas, numerosas outras questões poderiam 
ser lembradas, para elucidação das quais é decisiva a contribuição do direito comparado.

\section{9 - ORLENTAÇÃ̃ DE NOSSO ESTUDO.}

E ai temos a orientação a que deve obedecer o nosso estudo. Não iremos pesquisar leis, mas descobrir as concordâncias e as diferenças que facilitem ao cientista o descobri-las. Com esse estudo estaremos reunindo materiais que orientem as nossas reformas legislativas e proporcionem, através do direito comparado, melhor conhecimento do nosso direito e meio de resolver as dificuldades que se nos apresentarem.

Essas pesquisas das concordâncias e das diferenças constituirá a parte teórica, e o aproveitamento do material armazenado será a parte prática - servindo à interpretação do direito positivo, ao preenchimento de suas lacunas e ao aperfeicoamento da legislação. Desse estudo é que devem resultar as semelhanças e as diferenças que permitirão os princípios gerais do direito.

\section{0 - CONCEITO DO DIREITO COMPARADO.}

Levy Ullmann assim conceitúa o direito comparado. "Le droit comparé est une branche de la science juridique qui a pour objet le rapprochement systématique des institutions des prays civilisés" (43). Para Sujiyama (44) "la ciencia del derecho comparado es una de las disciplinas de la ciencia del derecho supranacional, fundada em el nuevo derecho natural que tiene por objeto realizar el progresso común del derecho nacional y del derecho mundial, mediante la comparación positiva y la aproximación siste-

(43) Rapport du droit international privé avec le droit comparé, in Bulletin de législation comparée 1932, p. 207.

(44) Ensayo de uma concepción sintética dei derecho comparado. 
matica de los derechos, y en caso necessario, por la construcción juridica".

Azulay (45) diz que o "direito comparado é uma disciplina que investiga as causas juridicas com o aparelho de Sociologia, estabelecendo, após uma comparação de sistemas jurídicos diversos, mas análogos, a finalidade de aprofundar a técnica jurídica dos institutos nacionais, ou bem fazer com que o legislador a utilize".

"El derecho comparado - diz Martinez Paz (46), es la disciplina juridica que se propone, pror meio de la investigación analítica, critica y comparativa de las legisladones vigentes, descubrir Ios principios fundamentales relativos y el fin de las instituciones juridicas y coordinarlas en un sistema de derecho positivo actual".

Outras definições poderiam ser trazidas à colação, mas para quê? Uma definição deve indicar a finalidade da disciplina, e, dada a multiplicidade de opinióes a respeito, é bem de ver como elas diversificariam.

Para nós, o direito civil comparado é o estudo do direito civil, pelo método comparativo, para lhe descobrir as concordâncias e as diferenças. A função prática desse estudo não deve ser compreendida no conceito, pois não estamos definindo uma arte.

Cabe aos cientistas, aos legisladores aos juristas, aos economistas, o aproveitar os estudos feitos, para as finalidades que se proponham.

(45) Os fundamentos do direito comparado.

746) Introdución al estudio del derecho civil comparado, 1934. 